scrutiny made of the various viscera, including the kidneys, but nothing indicating any organic lesion has ever been made out. Even to-day this heart that has given me so much anxiety shows only a shortened and high-pitched first sound and a little enlargement of the left ventricle.

The diagnosis of an intoxication - a toxemiaseems inevitable. Bearing in mind the history of the case, the direct history of the infectiousness of the husband, the pathological findings and the peculiar course of the disease, it is impossible to avoid the suggestion that we have been dealing with a gonotoxemia - if I may be allowed the word.

De Christmas, ${ }^{2}$ in a report of his researches on the gonococcus toxin and antitoxin, says that while still unable to produce gonorrhea, as ordinarly understood, in any of the lower animals, yet the introduction of the gonotoxin produces certuin definite effects, whether this gonotoxin be contained in the bodies of living or dead germs, in the filtered culture medium, or in the form of a glycerine extract of the precipitated toxin.

'To be brief, he describes these effects as being constitutional or constitutional and local, according as the toxin is injected directly into the blood, or as it is npplied locally to one of the tissues, as the subcutaneous tissue, the serous membranes, the anterior chamber of the eye, etc.

The constitutional symptoms are those of an intoxication, the gravity of which is proportionate to the dose of toxin; it is manifested by fever (by subnormal temperature, if the dose is excessive and quickly fatal), a rapid and pronounced loss of weight, complete anorexia, profuse diarrhea and the development of a state of cachexia and emaciation. 'The animal dies speedily or recovers only very slowly, and often dies in a state of gradual decline, the autopsy showing no apparent organic lesiou, the principal manifestation being a pronounced anemia with considerable diminution in the number of red globules. The immediate cause of death appears to be a pulmonary hyperemia.

The local reaction to the toxin is a pronounced inflammation with the formation of thick, yellow pus. Pus and exudate are sterile. 'These lesions have no tendency to spread; they disappear slowly and, when in the subcutaneous tissue, are characterized by a cicatricial retraction of the integument which is very slow in disappearing and which remains tender a long time.

While it is true that the effects of toxins on man and on the lower animals are not exactly parallel, nevertheless, they are akin, and the analogy between the condition of this patient and the results of De Christmus's experiments is striking.

As for the streptococcus antitoxin - it was used, first, because the streptococcus seems to be ubiquitous, and I did not feel able absolutely to exclude the possibility of its presence here; but, also, it was used because 1 have been much impressed with the experiments of Roux and Culmette, showing that "the serum of animals that have been immunized against certain viruses or poisons may be able to give immunity against certain other viruses or poisons." 'Thus, Roux hus shown that tetanus antitoxic serum is antitoxic also to snake venom; and that by rendering a rabbit refractory to rabies, it becomes immune against snake bites.

In the absence of a gonococcus antitoxin, the strep-

2 )e (hriatmes : Contribulion a lefitule du tionocoquo ot so '́oxlie, Anu. do l'Listitute Pusteur, Paris, A ugust, 1897, p. 609. tococcus antitoxin seemed the most available. Its effect on the pulse and temperature has been shown. Its effect on the general condition and appearance of the patient was more remarkable, and more impressive to those who saw it because it was so plainly evident and more permanent. It recalled the assortion of Metchnikoff that we have to do with not "antitoxins" but "stimulins," of which several may produce the same effect upon living cells.

No'sc- - Acting on Do Christmas's finding that in animals dying from gonotoxemia, the principal manifestation was a pronounced anemia with considerable diminution in the number of red globules, I bogin, December 18th (a fow days after making the above report), giving inlatations of oxygen to this pationt.

During the first administration, of ten minutes' duration, which I gave mysolf, 1 was surprised to note that the pulso foll from 116 to 104 ; during the niglit following this, it registered (lif, falling below 100 for tho first time since under the andministration of antitoxin, on November 15th. She was ordered oxygen for ten minutes' duration, four times a day.

In in few days, a change was noted in the skin, the grayish, cachotic hue markedly eloating up. The pulso maintained a lower range, generally botween 90 and 100 . Its irregularity, however, continued. Tho patient convalesced slowly and loft the hospital Jaumary $25,1898$.

\section{Clinical \&Department.}

\section{VELANDER'S NEW METHOD OF ADMINIS'TER-} ING UNGUEN'IUN HYDRARGYRI.

\author{
BY RICHARD HOQNER, At, D,
}

I TAKE the liberty to present a very iuteresting case - a pillow-case - which I think will be in the future a valuable instrumental means of administering unguentum hydrargyri.

Dr. Edv. Velander, professor in venereal disenses in Stockholm, Sweden, and head doctor at the very great St. Göran's Ilospital for venereal diseases in that city, has recently devised this pillow-case for the above named purpose.

My own experience in its use is limited to two patients. However, I found it so practical, effective, convenient and clean, that I do not hesitate to communicate the facts to you already.

Professor Velander is well known among the profession for the work he has done in this specialty of our art. 'The Velander method of curing soft chancre by heat is widely spread and adopted with or without modifications. His investigations some years ago on the absorption of mercury in unguentum hydrargyri led him to the conclusion that it is mostly, if not entirely, absorbed by inhalation of the evaporated mercury, and induced him to use in the administration of this drug a combined method of rubbing in the ointment and spreading it out on different parts of the body, and later the simple method of only spreading it over the skin. These facts are now well known.

This year he has finally given up spreading the ointment over the skin and relies entirely on the application of the ointment to the inner surface of a pillow-case, which is to be fastened about the patient's body, from the neck, downward. 'This method is now so generally accepted in Sweden that it is there almost the only one at present used in the general administration of mercury externully.

'The pillow.case is made of cheap cotton cloth. It measures 38 by 54 centimetres ( 15 by 21 inches), and

1 Romi before tho Clinlenl Soction of the Suflolk Bistrict Modion Socloty, looumbor 15, 1897. 
has ribbons for its suspension over the chest. The ribbons are placed two laterally at each edge, 12 centimetres (43 inclues) above the lower corners, and four upward, namely, two opposite each other at the upper edges, 6 centimetres ( $2+1$ inches) from the corners. The ribbons are about 64 by 1.5 centimetres ( 25 by 0.5 inches).

The pillow-case is suspended from the shoulders with the external part of its medicated side toward the body - that is, under the clothing - and is held in position by the ribbons which are tied around the waist and over the shoulders down to the waist ribbous. It is worn consecutively for ten days, alternating every twenty-four hours, from the front of the chest to the back, fresh ointment being supplied every night without wiping off the old. After ten days a new pillow-case is applied.

Baths are to be taken once or twice a week, the skin under the pillow-case being washed every night.

Dr. Velander uses, besides this ointment treatment, all necessary local treatment, etc., and with the ordinary attention to the month, he has not met more stomatitis than usual.

The quantity of ointment used is six grammes (13 drachms), of a strength of two hydrargyrum to four constituens; aud, as before said, it is spread every night over the same half of one of the insides of the pillow-slip. 'The best way to spread the ointment over the inside of the pillow-case is to spread it out over the outside and afterward turn the pillow-case outside in.

'This simple treatment is very convenient for the patient, as he can go about comfortably as usual, is not bothered with any painstaking rubbing, keeps himself easily clean, and at the same time can easily conceal his treatment.

'This pillow-case method is also very satisfactory for the doctor, as the mercury seems thus to be absorbed quicker, with less irritation.

\section{ghedital forogregg.}

\section{REPOR'T ON PROGRESS IN GYNECOLOGY.}

\section{BY KDWAHID RICYNOLJB, M.D.}

RETROVERSION AND RETROFLEXION OF THE UTERUS.

S. Pozzi ${ }^{1}$ considers that retroversion and retroflexion of the uterus are not distinct morbid entities. 'They occur under two conditions: (1)) relaxation of the ligaments or flexibility of the cervix, without adhesions, with or without lesions of the appendages, that is, a movable retrodeviation; (2) posterior adhesions, especially around the appenduges, after a perimetritis or perioöphoro sulpingitis, that is, a fixed or adherent retrodeviation. Movable retrodeviations without lesions of the appendages might better be termed excessive mobility of a uterus which has lost its fixity. The principal phenomena of a nervous and reflex character which they cause are independent of the direction of the deviation and are due to the mobility. All surgicul treatment which allows subsequent development of a preguant uterus can have only temporary results, as constant traction causes relaxation of the artificial attachment, and all which gives durable results interferes with subsequent gestations. The treatmont

1 kev. do Gyn., May and June, 1897. should be directed to the cure of the metritis or inflammation of the appendages, restoration of the lacerated or relaxed perineum by a plastic operation, and the use of a pessary which fixes the cervix by distending the posterior cul-de-sac, and an abdominal belt to regulate intra-abdominal pressure. In adherent retrodeviations the adhesions may bo broken up by massage or the sound, but this is dangerous. The principal norbid element is not the deviation or adhesions, but the condition of the uterus, tube or ovary, and it is to the latter that treatment should be directed. If the appendages are chiefly diseased with metritis, lapalotomy is usually indicated, breaking up adhesions, and performing ignipuncture and resection of partially diseased ovaries, or castration if the appendages are gravely involved. 'The uterus will then spontaneously resume its normal position. With bilateral lesions of the appendages and clironic metritis in women near the menopause or later, vaginal hysterectomy may bo preferable.

Retroversion and retroflexion of the uterus were discussed at tho German Gyuecological Congress in Leiprig. ${ }^{2}$

13. S. Schultze. Etiology. - (1) Relaxation of the uterine ligaments caused by pregnancy and puerperium; resorption proceeding from parametritis posterior; habitual constipation; continued recumbent position. (2) Fixation of cervix anteriorly through spontaneous and artificial scars (parametritis anterior, lacerations of cervix, discission of cervix, fistula). (3) Abnormal shortness of vagina, especially of anterior wall (puerile arrest of development, senile atrophy). (4) Habitual fulness of bladder. (5) Gaping vulva, the result of perineal lacerations; the everted anterior vaginal wall drags the cervix forward and the body is displaced backward. (6) Rarer causes are abnormal length of cervix, tumors of anterior uterine or cervical wall, incomplete descent of the ovaries, adhesions of ovaries and tubes posteriorly.

Proplyylaxis. - Prevention of over-distention aud habitual fulness of bladder, especially in childrenschool-teachers' attention must be drawn to this; prevention of catarrhal infection; closed undergarments; aseptic menstrual pads; repair of perineal defects; regulation of bowels; attention to obtain involution of puerperal uterus through the giving of ergot.

Bimanual palpation suflices for diagnosis; uterine sound is dangerous and unnecessary. 'The diagnosis of complications should be made under anesthesia.

Non-operative T'reatment. - Bimanual reposition; after this a pessary. Schultze uses celluloid pessaries, which are shaped according to position. In relaxed anterior wall he uses the sledge, otherwise 'Thomas's, Hodge's, or figure-of-eight pessary. 'The pessary must not separate the vulva nor project from it. Douches only necessary in first few days after menstruation. In ensuing pregnancy removal in the seventeenth week; if pessary fits well remove only every year. Permanent results are obtained by the duily use of cold enemata, which should also be taken after every defecution. During menstruation ergot is advised.

Frequent Complications. - Subinvolution, metritis, endometritis, oöphoritis, in recent cuses are best treated by reposition, while in old cases dilatation, irrigation, and curettement improve the tonus of the uterus and its ligaments. If reposition is difficult, recto-vaginoabdominal palpation under anesthesia; after this pes- 